\title{
Design and Implementation of Smart Electric Bike Eco-Friendly
}

\author{
Sunikshita Katoch, Rahul, Ranjit Kumar Bindal
}

\begin{abstract}
In this paper, we are concerning about the growing demand of energy all over the world, which motivate us to switch over renewable resource of energy. There are many different ways by which we can save energy in different sectors. Our main focus is on automobile sector where we are converting old petroleum bike to electric bike. In these electric bikes we use electrical motor (BLDC motor) instead of combustion engine as there is less pollution, low maintenance cost, reduces noise. These bikes utilize chemical energy stored in the rechargeable battery packs. This paper deals with the design and development of electric bike which make use of electric energy as primary source. There is a distribution for charging the battery emitting it from the main system.
\end{abstract}

Index Terms: Hybrid electrical vehicle, BLDC motor, electric bike, lithium-ion battery.

\section{INTRODUCTION}

The main reason to design the electric bike is to overcome the problem with the pollution and with the economy. Future E bike is the best technical application as a solution for the better world and upcoming generation. The $\mathrm{E}$ bike is a battery operated vehicle that is very economical with low maintenance cost and less pollution. E bikes are an attractive alternative to both conventional bicycles and traditional automobiles, providing an environmentally friendly, fun, efficient and convenient way to travel. E-bikes are driven with the help of battery which is coupled with electric motor.

E- Bike is the plug-in electrical vehicles with two or three wheels. The power on which this bike works is stored in a rechargeable battery which drives the motor. Now a day's these motorbikes are manufactured at a very large scale. Typical parts used in E-bike are BLDC motor, battery, controller, throttle, chain set. [1]

\section{COMPONENTS OF E-BIKE}

The e bike consists of following components

\section{Motor}

The motor is having rated power of $750 \mathrm{w}$ capacity with max $500 \mathrm{rpm}$ per min, their specifications are as follows:

Rated voltage - dc $48 \mathrm{v}$

Rated current -13.5 amp

Protection level -IP33

Insulation class $-\mathrm{f}$

Revised Manuscript Received on April 12, 2019.

Sunikshita Katoch, Electrical Engineering Department, Chandigarh University, Gharuan Mohali, India.

Rahul, Electrical Engineering Department, Chandigarh University, Gharuan Mohali, India.

Ranjit Kumar Bindal, Electrical Engineering Department, Chandigarh University, Gharuan Mohali, India.

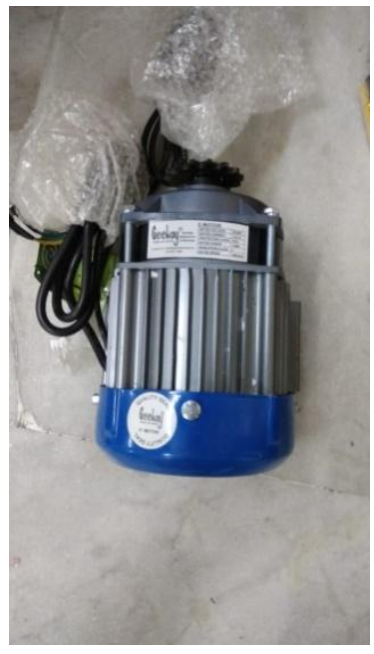

Fig: 1 BLDC motor

\section{Battery}

A lithium ion battery are the rechargeable battery which is used in many electric vehicles now a days in this battery the lithium ions moves from the negative electrode to the positive electrode during discharge and back when charging. It is more efficient as it is less in weight, high speed, no pollution, more reliable.

\section{Frame}

It is the core structure on which other parts are assembled, it supports the motor, provides base for the location of starring and supports the passenger or luggage, batteries also attached to the frame.

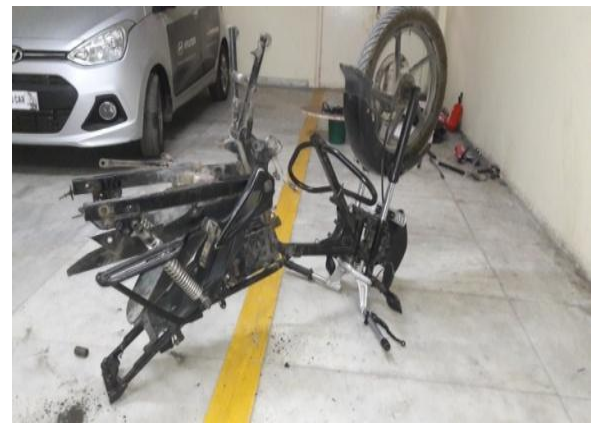

Fig: 2 frame of the e-bike

Breaking System

In this system, kinetic energy is converted into thermal energy by friction. It is used in band brake system which consists of spring loaded friction -shoe mechanism, which is driven with the help of hand lever. 


\section{Design And Implementation Of Smart Electric Bike Eco-Friendly}

\section{Chain set}

It is the more common type of chain drive which is used for transmission of mechanical power to long lasting \&better way of rotatory motion from one gear to another it is derived by a tooth head wheel called a sprocket it is simple, reliable and efficient.

\section{Sprocket}

It is the wheel with teeth which holds the chain they are used to transmit rotatory motion between to shafts. It is different from gear as it has many teeth \& where as gear consists of only one or two teeth. It is also different from pulley because the pulley works more smoothly [2].

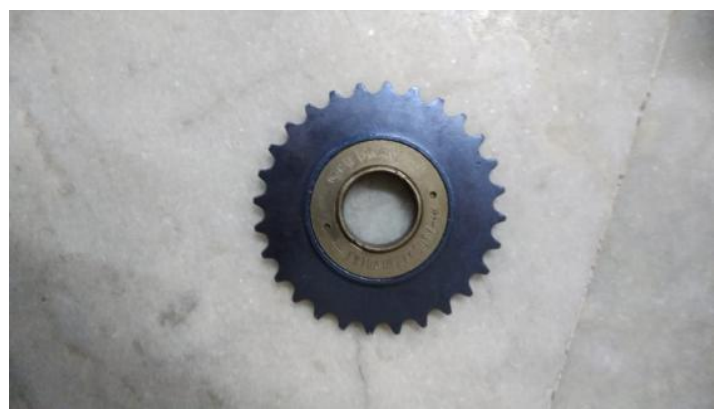

Fig: 3 Sprocket of the bike

\section{LITRATURA REVIEW}

A. JENNIFER DILL, GEOFFERY ROSE (2012) [3] clarified that Electric bicycles are progressively regular in China however are moderately uncommon in the United States. The meetings uncovered a few conceivable statistic markets for e-bicycles that could extend the bicycling populace: ladies, more established grown-ups, and individuals with physical impediments. Proprietors of e-bicycles noticed their capacity to travel longer separations and over slopes without any difficulty and to touch base at a goal, for example, work, less damp with sweat and less drained than a customary bike would permit. These highlights may beat a portion of the regular hindrances to bicycling for all socioeconomics. The vast majority of the talked with ebicycle proprietors utilized their e-bicycles to substitute for movement by either human-fueled bikes or customary engine vehicles. Thusly, the e-bicycle can address worries about medical issues identified with inertia, contamination, and other open strategy issues to which private vehicles contribute. Further research is expected to decide if explicit approaches are expected to expand reception of e-bicycles. The potential for strife between riders of e-bicycles and of standard bicycles due to speed differentials is a worry. Regardless of whether speed differentials will represent a noteworthy issue will depend not just on the degree of selection of e-bicycles however the qualities of the riders.

B. ELLIOTFISHMAN, CHRISTOPHER CHERRY (2016) [4] talked about that E-bicycles speak to one of the quickest developing sections of the vehicle showcase. More than 31 million e-bicycles were sold in 2012. Research has pursued this development and gives a combination of the most relevant subjects rising over the past on the expanding point of e-bicycles. The center is transport as opposed to recreational e-bicycle look into, just as the most basic research holes requiring consideration. China drives the world in e-bicycle deals, trailed by the Netherlands and Germany. E-bicycles can keep up speed with less exertion. E-bicycles are found to expand bike use. E-bicycles can possibly dislodge ordinary mechanized (inside burning) modes, yet there are open inquiries regarding their job in uprooting customary bikes. E-bicycles have been appeared to give medical advantages and a request of size less carbon dioxide than a vehicle venturing to every part of a similar separation. Security issues have developed as an arrangement issue in a few locales and e-bicycle numbers are currently moving toward levels in which satisfactory wellbeing information can be gathered. Research on ebicycles is still in its earliest stages. As e-bicycle utilization keeps on developing, so too will the requirement for further research, so as to give the fundamental information to illuminate strategy creators and industry.

\section{SIMON WASHINGTON, NARELLE HAWORTH} (2014) [5] clarified that there are as of now in excess of 700 urban communities working bicycle share programs. Indicated advantages of bicycle share incorporate adaptable versatility, physical movement, emanations and fuel use. Certain or express in the figuring of program benefits are presumptions with respect to the methods of movement supplanted by bicycle share ventures. An optional and remarkable common and support. These two parts are then consolidated to gauge bicycle offer's general commitment to changes in vehicle kilometers voyaged.

D. C.C.CHAN (2002) [6] talked about a reality where condition assurance and vitality preservation are developing concerns, the advancement of electric vehicles (EV) and half and half electric vehicles (HEV) has taken on a quickened pace. The fantasy of having industrially practical EVs and HEVs is turning into a reality. EVs and HEVs are step by step accessible in the market. This paper will give a diagram of the present status of electric and half breed vehicles worldwide and their cutting edge, with accentuation on the building logic and key innovations. The significance of the combination of innovations of vehicle, electric engine drive, hardware, vitality stockpiling, and controls and furthermore the significance of the reconciliation of society quality from government, industry, explore establishments, electric power utilities, and transportation experts are tended to. The test of EV commercialization is examined.

E. K.J.ASTROM, R.E.KLEIN (2005) [7] clarified that the elements of bikes is dissected from the point of view of control. Models of various multifaceted nature are exhibited, beginning with straightforward ones and closure with progressively practical models created from multimode programming. Models that catch fundamental conduct, for example, self-adjustment just as models that show troubles with back wheel controlling are considered. Encounters utilizing bikes in charge instruction alongside recommendations for the sake of entertainment and provocative examinations with demonstrated understudy fascination are introduced. At long last, bikes and clinical projects intended for kids with incapacities are depicted. 


\section{MATHEMATICAL CALCULATIONS \& RESULTS}

As the BLDC motor is being used with 750 watt power and $2100 \mathrm{rpm}$ with 48 volts and 13.5 amps. Motor can be reaching a peak current during starting equal to 15 amps[89].

$\mathrm{P}=2 * 3.14 * \mathrm{~N} * \mathrm{~T} / 60$

$750=2 * 3.14 * 2100 * \mathrm{~T} / 60$

$\mathrm{T}=3.41 \mathrm{~N} \mathrm{~m}=3412.19 \mathrm{~N}-\mathrm{mm}$

Chain drive reduction $=43 / 14=3.07: 1$

Wheel shaft torque $=\mathrm{T} * \mathrm{R}$ chain $=3412.1 * 3.07=10475.147$ $\mathrm{N}$ mm

Wheel shaft speed $=2100 / 3.07=684 \mathrm{rpm}$

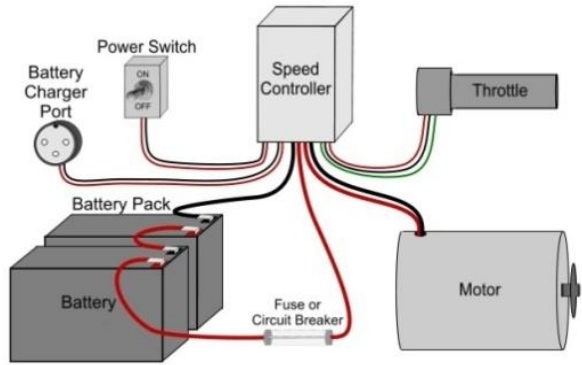

Fig.4 Block diagram of the e bike

\section{CONCLUSIONS}

Electric vehicles are the future of our world with the increasing consumption of non renewable resources such as petroleum, diesel which leads us to step our way towards the renewable sources such as solar hydro electric power and battery. There are alternative ways by which we can save energy. One of such way is electric bike; it is also the new way of transport which provides us easy way of transport to provide of any age. It is cheap source of transport and affordable to anyone. The motor used in this bike has high efficiency and the battery bank has less weight with high speed. These bikes are environmental friendly, needs less maintenance and can be also assembled to small component.

\section{ACKNOWLEDGMENT}

It Apart from the efforts of ours, the success of any project depends largely on the encouragement and guidelines of many others. We would like to show our appreciation to the respected Dr. Inderpreet kaur (HOD EE) for their support, we would also like to thank Dr. Ranjit Kumar Bindal (Assistant professor) for giving us this opportunity for making project based on next generation of E- vehicles. Without their assistance and dedicated involvement in every process, this project has never been accomplished.

Last but not the least we appreciate and thank all those people who contributed to this project directly or indirectly.

\section{REFERENCES}

1. S. Matey, A. Prabhu, "Design and Fabrication of Electric Bike" International Journal of Mechanical Engineering and Technology- Vol. 8 Issue 3- March 2017.

2. C.D. Ajudiya,M. M. trivedi, "Design and Development of EBike -A Review" Iconic Research and Engineering journalsVol.1 Issue 5- Nov 2017.
3. J. Dill, G. Rose, "Electric bikes and Transportation policyInsights from earlya dopters" SAGE Journals-Vol.2, Issue-1, 2012.

4. E. Fishman, C. Cherry, "E-bikes in the mainstreamReviewing a Decade of research"- Vol 36 Issue 1, 2016.

5. S.Washington, N. Haworth, "Bike shares impact on car useEvidence from the United states, Great Britain, and Australia"- Vol. 31,PP. 13-20, 2014.

6. C. C. Chan "The state of the art of electric and hybrid vehicles "Proceeding to IEEE, Vol. 90 Issue 2, PP. 247-275, 2017.

7. K.J. Astros, R.E. Klein, "Bicycle dynamics and control Adapted bicycles for education and research" IEEE control system magazine, Vol. 25 Issue 4, pp.26-47, 2017

8. P. Zhang., "Industrial Control Technology: A Handbook for Engineers and Researchers".

9. https://www.researchgate.net/publication/224299571_Electric _bicycle_using_batteries_and_supercapacitors

\section{AUTHORS PROFILE}

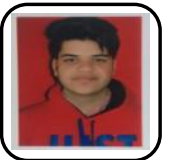

Rahul Final year student B.tech of Electrical Engineering From Chandigarh University.(2015-2019)

Sunikshita Katoch Final year student B.tech of Electrical Engineering From Chandigarh University.(2015-2019).Diploma holder from Govt. Polytechnical. Collage, HAMIRPUR (HP).

Ranjit Kumar Bindal $\mathrm{He}$ received his B.Tech in Electrical Engineering from PTU, Jalandhar, Punjab in 2002 and M.Tech in 2008 in Power Engineering from PTU, Jalandhar. 